\title{
Histological and Histomorphometric Evaluation of Anterior Part of Rats Tongue Exposed to Passive Cigarette Smoking
}

\author{
Original \\ Article \\ Salwa Farid Ahmed \\ Health Radiation Research Dept., National Centre for Radiation Research and
Technology (NCRRT), Atomic Energy Authority
}

\begin{abstract}
Tobacco causes multiple human malignancies including cancers of the lung, oral cavity, pharynx, stomach, liver and cervix. The current study aimed to investigate the effect of passive cigarette smoke on histological feature of anterior part of tongue and filiform and fungiform lingual papillae. Twelve male albino rats were divided in to two groups. One served as control while the other exposed to passive cigarette smoke for 60 days. Tongues specimens underwent histopathological and histomorphometric analysis. The tongue of passive smoking group represented pleomorphic filiform papillae with excessive keratin formation, marked disappearance of secondary papillae with flattening of the basement membrane. The fungiform papillae were smaller in size having thin keratin layer and some of them had degenerated taste bud. The serous acini of the anterior part showed mild vacuolization and inflammatory infiltration in the connective tissue stroma. The ventral surface showed decreased epithelial thickness, basement membrane irregularity and thinning of the keratin layer. Histomorphometric analysis showed decreased diameter of the filiform in response to passive smoking while its length differ according to its location; papillae at tip had normal length, at dorsal surface became elongated while those near the root had a decreased length. In conclusion, passive smoking had a deleterious effects on the histological structure of anterior part of tongue. In addition, it affected the morphology of filiform and fungiform lingual papillae.
\end{abstract}

Key Words: Histomorphometry, histology, lingual papillae, passive smoking; tongue.

Received: 03 October 2018, Accepted: 14 Feburay 2019

Corresponding Author: Salwa Farid Ahmed, Health Radiation Research Dept., National Centre for Radiation Research and Technology (NCRRT), Atomic Energy Authority, Ahmed El Zomor St. 3 P.O. Box 9516- Nasr City, Cairo, Egypt, Tel: +20 1010257151, E-mail: salwaa_fared@yahoo.com

ISSN: 2090-097X, October 2018, Vol. 9, No. 4

\section{INTRODUCTION}

Tobacco use contributes to the development of various human malignancies mainly cancers of oral cavity, lung, pharynx, esophagus, stomach, liver, pancreas, kidney, bladder, and cervix ${ }^{[1]}$. Smoking does not possess a danger for only smokers' health, but it extends also to affect the neighboring nonsmokers who exposed to tobacco smoke with its constituents of toxic substances in what called passive smoking ${ }^{[2]}$. The cigarette smoke contains numerous toxicants about 69 of them are considered carcinogens ${ }^{[3]}$. Smoking is not only a common risk factor for cancer development but it also negatively affect the outcome of cancer treatment $t^{[4]}$, modify the efficacy of chemo preventive substances ${ }^{[5]}$ and increases the hazard of second primary tumors and death as well[ ${ }^{[6]}$. Passive smoking was found significantly associated with increased risk for invasive bacterial diseases and respiratory infection in infants, asthma and invasive meningococcal disease in children and cancer, stroke and allergic diseases in adults ${ }^{[7]}$. Both active and passive smoking were found to evenly increase the risk of certain cancers ${ }^{[8]}$. However, the influence of passive smoking on general health stays unclear and controversial.

Smoking negatively affect the general condition of the oral cavity extending from only staining of the teeth and dental restoration to alteration of taste and smell sensitivity with development of oral candidiasis, black hairy tongue, smoker's melanosis, dental caries, gingival recession and periodontal disease that may end with precancer and cancer lesions ${ }^{[9]}$. The tongue is an important strong muscular organ essential for coughing, speech, oral transport, suckling, swallowing, taste and sensation of different stimuli types ${ }^{[10]}$. It can be to a large extent a key indicator for the general health condition of the body and a marker for many diseases.

The effect on passive smoking on tongue epithelium and sensory function was studied but controversy remains. In addition, there are limited researches on effect of passive smoking on different tongue components morphology. ccordingly, the aim of the present study is to evaluate the morphological changes of anterior part of tongue and filiform and fungiform lingual papillae in rats exposed to chronic passive cigarette smoking.

\section{MATERIALS AND METHODS}

\section{Animals:}

Twelve adult male Swiss albino rats, weighing $200 \pm 20$ g, obtained from the National Research Center (Dokki, Giza, Egypt) were housed in standard plastic cages. The rats were maintained with free access to standard laboratory pellet chow and water ad libitum. 
They were kept under controlled conditions of temperature $(27 \pm 30 \mathrm{C})$ and humidity $(60 \pm 5 \%)$ with $12 \mathrm{~h}$ light $/ 12 \mathrm{~h}$ dark cycles in well ventilated cages. The experimental protocol applied was accepted by the Department of Animal care, Cairo University that adhered to the European Communities Council guiding principles for the care and use of Laboratory animals. After an acclimatization period of 7 days, rats were randomly allocated and divided into two groups, 6 animals each. Group $\mathrm{C}$ where rats served as control animals and group PS in which rats were exposed to passive cigarette smoke for 60 days.

\section{Passive smoking facilities:}

The rats of PS group exposed daily to inhalation of smoke produced by two cigarettes lit four times a day, $30 \mathrm{~min}$ for each period, for 60 days. The inhalation of cigarette smoke was achieved in a glass cabin $(100 \times 50 \times$ $20 \mathrm{~cm}$ ) with the help of an aquarium air pump. One end of a plastic tube was implanted into the air pump and placed into the glass container with a cigarette on the other end. There are many small holes that allow the smoke to get away. Non-filtered commercially available cigarettes were used that provided $13 \mathrm{mg}$ of tar; $0.8 \mathrm{mg}$ of nicotine and 14 $\mathrm{mg}$ of carbon monoxide for each one. Control rats in group $\mathrm{C}$ allowed breathing normal clean air.

\section{The studied parameters:}

At the end of the experimental period (60 days) the rats were euthanized by over dose of Ketamine. After sacrificing the animals, the tongue specimens was fixed in $10 \%$ formalin and embedded in paraffin. Sections were cut at a thickness of $5 \mu \mathrm{m}$ and stained with hematoxylin and eosin (H\&E). Histopathological changes of the tongue were observed under the light microscope through pathologists. The length, diameter at base and apex $(\mu \mathrm{m})$ and area ( $\mathrm{mm} 2)$ of different filiform and fungiform lingual papillae were measured in 5 histological fields (x400) randomly captured with a digitized image analysis system using the software Leica Qwin 500.

\section{Statistical analysis:}

Data were expressed as mean \pm standard deviation (SD). Two-sample t-test was performed to compare group differences using Statgraphics XVII statistical software. $\mathrm{P}<0.05$ was considered statistically significant.

\section{RESULTS}

\section{Histopathological examination:}

The histological examinations of the dorsal surface of tongue section of the control group showed stratified squamous epithelium of normal thickness and keratinization with underlying loose connective tissue containing blood vessels. The anterior part of the tongue (tip) revealed uniformly distributed filiform papillae of normal, shape and dimension. Normal mushroom shaped fungiform papillae were found with the presence of the taste bud at its apical end. The body of the tongue showed normal shaped filiform papillae that were shorter in length and wider in the base diameter when compared to those of the tongue tip. There are thick layer of normal skeletal muscle bundles running in different directions and separated by connective tissue containing many serous and mucous minor salivary glands (Fig. 1, A and B). The ventral surface consisted of keratinized stratified squamous epithelium underlined by connective tissue containing blood capillaries and vessels and layer of striated muscles (Fig. 1, C).

The tongue of the rats exposed to passive smoking for 60 days represented many pathological changes. The filiform at the tip of the tongue were pleomorphic with excessive keratin formation, some were distorted with decreased height, and others appeared elongated with decreased diameter. There is marked disappearance of secondary papillae with flattening of the basement membrane. The supporting connective tissue was almost lost in many areas. At the body of the tongue, the filiform papillae appeared elongated and thin with excessive keratin formation. There is loss of the secondary papillae in few areas with normal underlying connective tissue. The filiform papillae near the root of the tongue were normal in shape with normal secondary papillae and supporting connective tissue. The dome shaped fungiform papillae were smaller in length having thin keratin layer, widen base and some of them had degenerated taste bud. The muscle fibers were normal in appearance. The mucous acini were normal while the serous one of von Ebner's glands in the posterior part of the tongue showed mild vacuolization in addition to inflammatory infiltration in the connective tissue stroma (Fig. 2, A and B). The ventral surface showed decreased epithelial thickness, basement membrane irregularity and thinning of the keratin layer. The underlying connective tissue showed reduced cellularity and contained many capillaries and blood vessels (Fig. 2, C).

\section{Histomorphometric analysis:}

Data from table (1) revealed that the effect of passive smoking on different lingual papillae is quite different. The filiform at the tip of the tongue had a length more or less similar to the control one while its diameter at the base significantly decreased. The length of the filiform at the dorsal surface of the tongue significantly increased as compared to the control however, its base diameter significantly decreased. The filiform papillae near the root of the tongue showed a significant reduction in both its length and base diameter as compared to control papillae. The fungiform papillae length was significantly decreased whereas its diameter at the base significantly increased. The diameter at its apex did not significantly differ from control fungiform papillae. The areas of different filiform and fungiform papillae were significantly decreased as compared to the control except the filiform located at the dorsal surface where the difference was not significant (Fig. 3). 


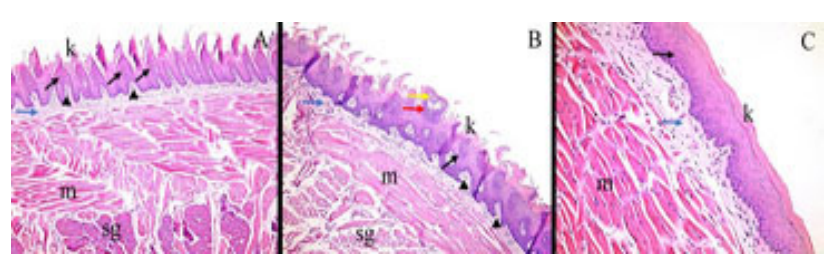

Fig. 1: Photomicrographs ( $\mathrm{A}$ and $\mathrm{B}$ ) of the dorsal surface of tongue section of group $\mathrm{C}$ showing normal, regular, slender filiform papillae (black arrow), thin keratin layer (k), secondary papillae (arrowheads), underlying connective tissue (blue arrow), muscle fibers (m), salivary glands (sg), mushroom shape fungiform papillae (red arrow), apical taste bud (yellow arrow). (H. \&E. x100) and (C) of the ventral surface of tongue section of group $\mathrm{C}$ showing normal epithelium (black arrow), thin uniform keratin layer $(\mathrm{k})$, underlying connective tissue (blue arrow) and muscle fibers (m). (H. \&E. x200)

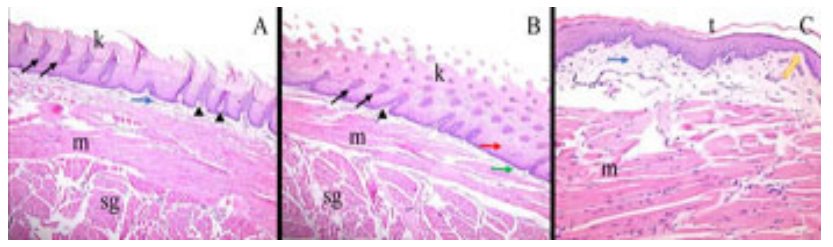

Fig. 2: Photomicrograph (A and B) of the dorsal surface of tongue section of group PS showing filiform papillae with disappeared secondary papillae (black arrows), thick keratin layer (k), secondary papillae (arrowheads), underlying connective tissue (blue arrow), muscle fibers (m) and salivary glands (sg), epithelial hyperplasia (red arrow), diminished underlying connective tissue (green arrow). (H. \&E. x100) and (C) of the ventral surface of tongue section of group PS showing reduced epithelial thickness with irregular basement membrane (yellow arrow), thinning of the keratin layer ( $\mathrm{t}$ ), underlying connective tissue (blue arrow) and muscle fibers (m). (H. \&E. x200)

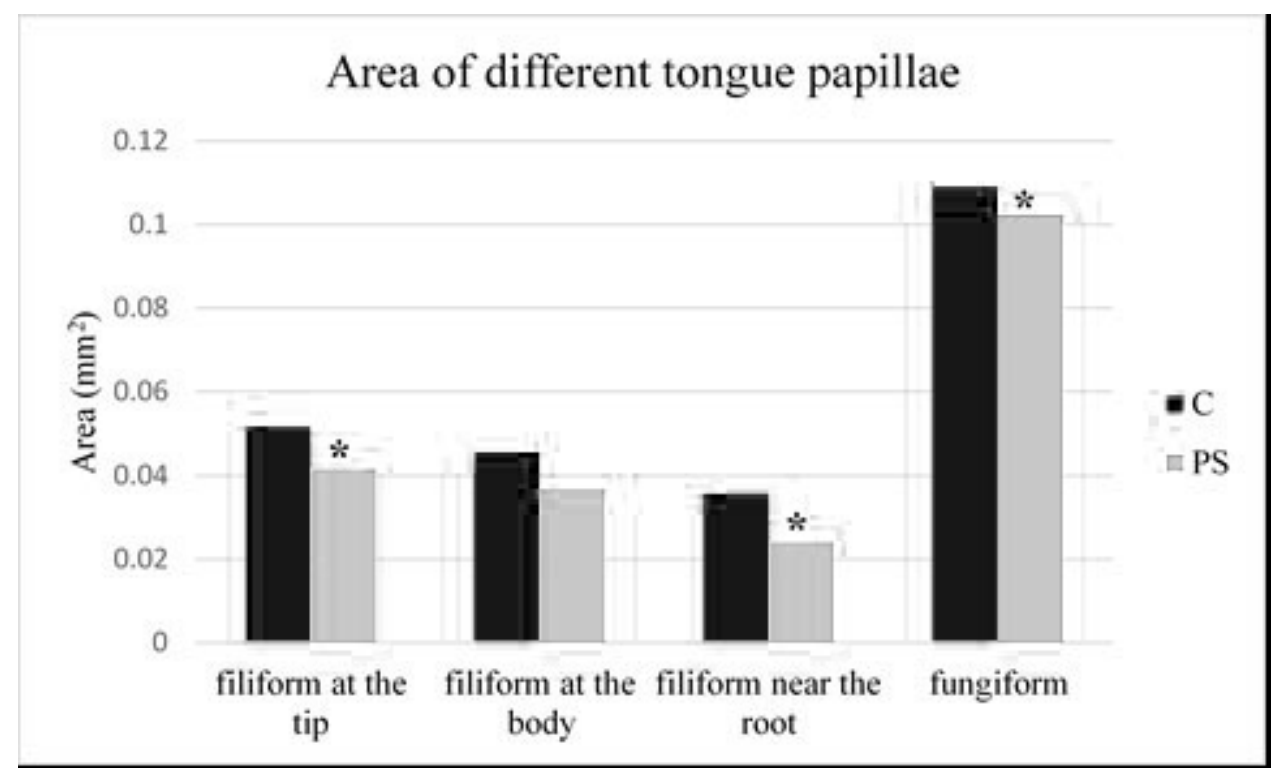

Fig. 3: A chart representing the area of different filiform and fungiform tongue papillae of control (C) and passive smoking (PS) groups.

*Means significant difference at $5 \%$

Table 1: Some morphometric parameters of the different filiform and fungiform tongue papillae of control (C) and passive smoking (PS) groups

\begin{tabular}{|c|c|c|c|c|c|c|}
\hline \multirow[b]{2}{*}{ Group } & \multicolumn{2}{|c|}{ Length $(\mu \mathrm{m})$} & \multicolumn{2}{|c|}{ Diameter at base $(\mu \mathrm{m})$} & \multicolumn{2}{|c|}{ Diameter at apex $(\mu \mathrm{m})$} \\
\hline & $\mathrm{C}$ & PS & $\mathrm{C}$ & PS & $\mathrm{C}$ & PS \\
\hline Filiform papillae at tip of the tongue & $371 \pm 11.6$ & $368 \pm 5.6$ & $109 \pm 7.3$ & $80 \pm 5.2 *$ & & \\
\hline Filiform papillae at dorsal surface of the tongue & $321 \pm 7.8$ & $369 \pm 12.0^{*}$ & $125 \pm 2.8$ & $74 \pm 9.0^{*}$ & & \\
\hline Filiform papillae near the root of the tongue & $266 \pm 3.5$ & $228 \pm 2.6^{*}$ & $126 \pm 2.8$ & $105 \pm 2.9 *$ & & \\
\hline Fungiform papillae & $287 \pm 0.93$ & $267 \pm 3.6^{*}$ & $149 \pm 3.9$ & $171 \pm 3.9 *$ & $282 \pm 3.2$ & $284 \pm 6.0$ \\
\hline
\end{tabular}

*Means significant difference at 5\% 


\section{DISCUSSION}

Cigarette smoking is one of the most deleterious agents affecting individual's health and increasing the risk for many diseases ${ }^{[11]}$. Several studies revealed increased association between passive smoking and development of cancer ${ }^{[12 \& 13]}$. In this study, the rats exposed to smoke of two cigarettes/ four times a day/ 60 days and then their tongues were examined histologically and morphometrically. The overall results of this study proved that passive smoking has very noxious effect on anterior part of the tongue including filiform and fungiform papillae. This is in harmony with other studies that pointed those nonsmokers who had exposed to passive smoking developed systemic diseases more likely than those not exposed to passive smoking ${ }^{[14]}$.

Histological tongue examination of passive smoking group revealed pleomorphic filiform and fungiform papillae, some were elongated while the other were diminished in size with disappearance of secondary papillae. These results were in harmony with Harada et al., ${ }^{[15]}$ who found disorganized and distorted tongue papillae of hamsters exposed to cigarette smoke. Another study revealed that the filiform tongue papillae of the tobacco exposed animals were irregularly displayed and flattened ${ }^{[16]}$. In addition, some papillae showed atrophic taste bud or even lost with excessive keratinization. These findings were consistent with Pavlos, ${ }^{[17]}$ who found altered taste sensitivity with smoking that range from distortion to diminished taste sense. These changes were associated with areas of atrophic papillary structures and papillae of thick and irregular surface and elongated blood vessels ${ }^{[17]}$. Additionally, smoking significantly increased the threshold for perception of different taste stimuli ${ }^{[18 \& 19]}$.

The epithelial hyperplasia and excessive keratin formation detected in passive smoking group could also be detected by Taybos, ${ }^{[20]}$ who reported that tobacco smokes had a deleterious effects on the surface epithelium with increased pigmentation and thickening in addition to the minor salivary glands. In the present study the mucous acini were not affected by the passive smoking in contrast to the serous one that revealed mild acinar vacuolization with inflammatory infiltration of the connective tissue stroma. Similarly, the passive smoking negatively affected the major salivary glands which represented pleomorphic serous acini with widen inter space filled with extracellular matrix, pyknotic and hyper stained nuclei, an inflammatory infiltrate and accumulated type I collagen in the connective tissue stroma ${ }^{[21]}$.

The overall effect of smoking could be attributed to its local effect through induction of vasoconstriction and reduction of the oxygen tension that provides suitable condition aerobic bacteria colonization ${ }^{[22 \& 23]}$. Regarding the systemic effect, the nicotine harmfully affect the functional capacity of the fibroblast through elevation of the collagenase production leading to diminished production of both fibronectin and collagen ${ }^{[24 \& 25]}$. Additionally, the volatile component in the cigarette smoke inhibited chemotaxis, phagocytosis of oral and peripheral neutrophil and impaired antibody production through decreasing the proliferating capacity of T cell which affects B cell function and antibody generation ${ }^{[22]}$.

\section{CONCLUSION}

Exposure to passive smoke, not only active smoking, is associated with pathological changes in both dorsal and ventral surface of anterior part of the tongue including filiform and fungiform papillae in addition to affection of the minor salivary glands.

\section{CONFLICT OF INTEREST}

There is no conflict of interests regarding the publication of this article.

\section{REFERENCES}

1. World Health Organization. International Agency for Research on Cancer. IARC Monographs on the Evaluation of Carcinogenic Risks to Humans, Tobacco smoke and involuntary smoking. IARC 2004: 83: 1-1438.

2. Jamrozik K. Estimate of deaths attributable to passive smoking among UK adults: database analysis. B M J 2005: 330: 812.

3. Hoffmann D, Hoffmann I. The changing cigarette: chemical studies and bioassays. Smoking and tobacco control monograph, 13th ed, 2001: $159-192$.

4. Hickey K, Do KA, Green A. Smoking and prostate cancer. Epidemiol Rev 2001: 23: 115 - 125.

5. Mayne ST, Lippman SM. Cigarettes: a smoking gun in cancer chemoprevention. J Natl Cancer Inst 2005: 97: 1319-1321.

6. Khuri FR, Lee JJ, Lippman SM, Kim ES, Cooper JS, Benner SE, Winn R, Pajak TF, Williams B, Shenouda G, Hodson I, Fu K, Shin DM, Vokes EE, Feng L, Geopfert H, Hong WK. Randomized phase III trial of low-dose isotretinoin for prevention of second primary tumors in stage I and II head and neck cancer patients. J Natl Cancer Inst 2006: 98: $441-450$.

7. Cao S, Yang C, Gan Y, Lu Z. The health effects of passive smoking: an overview of systematic reviews based on observational epidemiological evidence. PloS One 2015: 10: e0139907.

8. Boyle P, Autier P, Bartelink H, Baselga J, Boffetta P, Burn J, Burns HJG, Christensen L, Denis L, Dicato M, Diehl V, Doll R, Franceschi S, Gillis CR, Gray N, Griciute L, Hackshaw A, Kasler M, Kogevinas M, Kvinnsland S, La Vecchia C, Levi F, McVie JG, Maisonneuve P, Martin-Moreno JM, Bishop JN, Oleari F, Perrin P, Quinn M, Richards M, Ringborg U, Scully C, Siracka E, Storm H, Tubiana M, Tursz T, Veronesi U, Wald N, Weber W, Zaridze 
DG, Zatonski W, zur Hausen H. European Code Against Cancer and scientific justification: third version (2003). Ann Oncol 2003: 14: 973 - 1005.

9. Reibel J. Tobacco and oral diseases. Med Princ Pract 2033: 12: 22 - 32.

10. Du Toit DF. The tongue: structure and function relevant to disease and oral health. SADJ 2003: 58: 375383-380,376-.

11. World Health Organization. WHO report on the global tobacco epidemic: warning about the dangers of tobacco. Geneva. 2011

12. Johnson KC. Accumulating evidence on passive and active smoking and breast cancer risk. Int $\mathrm{J}$ Cancer 2005: 117: 619 - 628.

13. Johnson KC, Miller AB, Collishaw NE, Palmer JR, Hammond SK, Salmon AG, Cantor KP, Miller MD, Boyd NF, Millar J, Turcotte F. Active smoking and secondhand smoke increase breast cancer risk: the report of the Canadian Expert Panel on Tobacco Smoke and Breast Cancer Risk (2009). Tob Control 2009:, 20: e2.

14. Arbes SJJr, Agústsdóttir H, Slade GD. Environmental tobacco smoke and periodontal disease in the United States. Am J Public Health 2001: 91: 253 - 257.

15. Harada T, Enomoto A, Kitazawa T, Maita K, Shirasu Y. Oral leukoplakia and costochondral hyperplasia induced by diethylnitrosamine in hamsters exposed to cigarette smoke with or without dietary vitamin C. Vet Pathol 1987: 24: $257-264$

16. Martins RH, Goncalves TM, Madeira SL, Dias NH, de Oliveira Semenzati G. Scanning electron microscopy of the tongue, pharynx, and larynx of rats exposed to cigarette smoke. J Voice 2014: 28: $287-290$.

17. Pavlos P, Vasilios N, Antonia A, Dimitrios K, Georgios K, Georgios A. Evaluation of young smokers and non-smokers with Electrogustometry and Contact Endoscopy. BMC Ear Nose Throat Disord 2009: 9: 9 .

18. Sato K, Endo S, Tomita H. Sensitivity of three loci on the tongue and soft palate to four basic tastes in smokers and non-smokers. Acta Oto-Laryngol 2002: 122: $74-82$.

19. Yamauchi Y, Endo S, Yoshimura I. A new wholemouth gustatory test procedure: II. Effects of aging, gender and smoking. Acta Oto-Laryngol 2002: 122: 49 - 59.

20. Taybos G. Oral changes associated with tobacco use. Am J Med Sci 2003: 326: 179 - 182.

21. Ferragut JM, da Cunha MR, Carvalho CA, Isayama RN, Caldeira EJ. Epithelial-stromal interactions in salivary glands of rats exposed to chronic passive smoking. Arch Oral Biol 2011: 56: 580 - 587.

22. Salvi GE, Lawrence HP, Offenbacher S, Beck JD. Influence of risk factors on the pathogenesis of periodontitis. Periodontal 2000 1997: 14: $173-201$

23. Hildebolt CF, Pilgram TK, Yokoyama-Crothers N, Vannier MW, Dotson M, Muckerman J, Hauser J, Cohen S, Kardaris EE, Hanes P, Shrout MK, Civitelli R. Alveolar bone height and postcranial bone mineral density: negative effects of cigarette smoking and parity. J periodontal 2000: 71: $683-689$.

24. Cattaneo V, Cetta G, Rota C, Vezzoni F, Rota MT, Gallanti A, Boratto R, Poggi P. Volatile components of cigarette smoke: effect of acrolein and acetaldehyde on human gingival fibroblasts in vitro. J periodontal 2000: 71: 425 - 432.

25. Tanur E, McQuade MJ, McPherson JC, AlHashimi IH, Rivera-Hidalgo F. Effects of nicotine on the strength of attachment of gingival fibroblasts to glass and non-diseased human root surfaces. J periodontal 2000: 71: 717 - 722 . 